Journal of Forensic Economics 14(1), 2001, pp. 3- 8

(C) 2001 by the National Association of Forensic Economics

\title{
Introduction to the Whole-time Concept
}

\author{
Kurt V. Krueger, John O. Ward and Gary R. Albrecht*
}

\section{Introduction}

The value of time is a relevant aspect of economic valuations of life. The value of time affects the optimum combination of inputs in home production, the investments made by a household for its economic improvement, the household's supply of labor for market employment and its demand for goods, and other household economic decisions. This paper introduces a whole-time methodology useful to forensic economics in valuing a number of economic losses associated with personal injury. The whole-time approach originates the concept that since all of the uses of time have a direct bearing on economic value in life, the whole amount of time available for productive use is a direct input to (or a subset of) the totality of life's economic value. Within the wholetime concept, personal injury economic damages are the measurable changes in economic welfare as result of a reduction in the productive use of time because of injury.

A pre-cursor methodology in the forensic economic literature addressing economic valuation of life is hedonics. The methodology of hedonics was one of the first attempts to incorporate the totality of life's economic value in the calculation of personal injury damages. Unlike the whole-time concept, the hedonic approach is unable to make direct assignment of economic value to specific time. However, the hedonic methodology, like the whole-time concept, incorporates the principle that the economic value of time is relevant to the totality of life's economic value. ${ }^{1}$ While there are variants to the hedonic methods, the approach most commonly discussed (the willingness-to-pay method) assumes that the economic behavior of a population in the avoidance of death provides insight to the totality of economic value assigned by the population to life. There are hedonic models that do not segment economic values in life and other models calculate a residual enjoyment of life as the difference between the estimate of the totality of life's economic value and other measurable economic values based in time such as earnings and household work services. In summary, the common feature of all hedonic models is their beginning at the highest level of economic valuation, the totality of life's economic value, before addressing subset economic values in life. In contrast, the whole-time concept begins at the root level of economic valuation-how an individual values time for production and consumption-to work upward towards (but not necessarily reaching) the totality of life's economic value.

*Kurt V. Krueger, John Ward Economics, Prairie Village, KS; John O. Ward, Chair and Professor of Economics, University of Missouri-Kansas City, Kansas City, MO; Gary R. Albrecht, Albrecht Economics, Winston-Salem, NC.

${ }^{1}$ For a complete discussion of hedonics, see Ireland and Ward (eds.), 1996. 
The purpose of this short paper is to introduce the whole-time concept in forensic economics and to offer, as a simple example, a method for estimation of economic damages specific to a personal injury plaintiff that includes both work and non-work time. We begin the paper with an introduction to the microeconomic foundations of the whole-time concept. We show the change in economic welfare resulting from injury and the whole-time method of economic restoration. Before concluding, we present a hypothetical calculation of wholetime economic damages resulting from an injury reducing the productive use of time.

\section{Loss in the Productive Use of Time}

In human behavior theory, economists measure economic value in life using the concept of utility or satisfaction derived from consumption. Gary Becker, the 1992 Nobel Prize winner in economics, provides an analytical model, in the form of three basic interactive utility functions addressing human capital investments and market decisions. Becker (1991) observes that,

A more complicated and more realistic version of the theory recognizes that each person allocates time as well as money income to different activities, receives income from time spent in the marketplace, and receives utility from time spent eating, sleeping, watching television, gardening, and participating in many other activities. The utility function... then is extended to $U=U(x 1 \ldots x n, t 1, . ., t r)$, where $t$ is the time spent on the $\mathrm{j}^{\text {th }}$ activity. (pg. 21)

Becker then maximizes this function given a time-budget constraint and a money-income constraint such that:

The marginal utility from all uses of time are equal in equilibrium because they have the same price (w), and the marginal rate of substitution between time and each good equals the 'real' wage rate, where the price deflator is the price of the good. (pg. 22)

Utilizing Becker's approach, the concept of the value of life consists of additive utility functions whose values, on the margin, are equal. Human capital investment influences the utility functions: monetary earning capacity increases with investment, and, likewise, the utility values of service and time spent at consumption increases with investment. In this microeconomic theory, the concept of the economic value in life is dynamic and predictable within the structure of the utility model. Under the utility approach, the marginal utility of the usage of work and non-work time by a surgeon, for example, as based on his or her allocation of time and human capital investment, has a higher market value than that of a plumber. Based on microeconomic principles, the whole-time economic model allows different valuations of work and non-work time across individuals.

With maximizing behavior, Becker demonstrates that all uses of time have the same value (or price) to an individual. When maximizing utility, a total 
resource constraint, consisting of goods and time, limits an individual's enjoyment capabilities. Becker writes this constraint as: ${ }^{2}$

where,

$$
\sum p_{i} x_{i}+\sum T_{i} \bar{w}=V+T \bar{w}
$$

$$
\begin{aligned}
\mathrm{p}_{\mathrm{i}}= & \text { price of } \mathrm{x}_{\mathrm{i}} \\
\mathrm{x}_{\mathrm{i}}= & \text { vector of market goods used in production of } \mathrm{Z}_{\mathrm{i}} \\
\mathrm{T}_{\mathrm{i}}= & \text { vector of time inputs used in production of } \mathrm{Z}_{\mathrm{i}} \\
\mathrm{Z}_{\mathrm{i}}= & \text { commodities produced and consumed by household where } \\
& \mathrm{Z}_{\mathrm{i}}=\mathrm{f}_{\mathrm{i}}\left(\mathrm{x}_{\mathrm{i}}, \mathrm{T}_{\mathrm{i}}\right) \\
\overline{\mathrm{w}}= & \text { earnings per unit of } \mathrm{T}_{\mathrm{w}} \text { (hours worked) } \\
\mathrm{V}= & \text { other non-wage income } \\
\mathrm{T}= & \text { vector of total time available thus } \mathrm{T} \overline{\mathrm{w}} \text { equals total earnings } \\
& \text { capability ("full income") }
\end{aligned}
$$

To interpret this constraint, we will assume that $\overline{\mathrm{w}}$ is a constant. This assumption is reasonable when $\mathrm{T}$, the vector of total time available, does not include the time necessary to maintain the human body for sustaining productivity. For example, the hours required for physical and mental maintenance to allow $\overline{\mathrm{w}}$ are not included in $\mathrm{T}$ so that $\mathrm{T}$ may be, for example, 14 hours per day. ${ }^{3}$

Since money, time, and goods can be equally substituted with each other, the total resource constraint is often called the full-income constraint. We show the full-income approach to maximization of economic welfare in Figure 1. The utility function is represented by $\mathrm{U}$. An individual derives utility from the consumption of commodities, $\mathrm{Z}_{\mathrm{i}}$, which he or she produces by combining market goods and time. For example, an individual purchases a market good such as a book, $\mathrm{x}_{1}$, and combines the market good with an amount of time, $\mathrm{t}_{1}$, to produce a commodity that is consumed, $\mathrm{Z}_{1}$, in order to derive utility, $\mathrm{U}$. With respect to the full-income budget constraint, consider first the restraint represented by the line II. This budget constraint assumes that V=0. Any point on line II is a combination of the hours of time used in the production of $\mathrm{Z}_{\mathrm{i}}, \mathrm{t}$, times the wage rate, $w$, plus the price of market goods, $p$, times the amount of market goods used in the production of $\mathrm{Z}_{\mathrm{i}}$, $\mathrm{x}$. With the assumption $\mathrm{V}=0$ and using a one-period model, the value of the market goods used in the production of $\mathrm{Z}_{\mathrm{i}}$ is equal to the value of time devoted to acquiring market goods. ${ }^{4}$ With the utility function $\mathrm{U}$ and the full-income constraint II, maximum economic welfare occurs at point $\mathrm{C}$. At $\mathrm{C}$, the marginal value of time used in the production of $\mathrm{Z}_{\mathrm{i}}$ is equal to the marginal value of time used to acquire market goods. An individual's consumption of market goods is measured by the distance $0 \mathrm{~A}$ and the value of time used in the production of $\mathrm{Z}_{\mathrm{i}}$ is measured by $0 \mathrm{~B}$.

${ }^{2}$ Becker, Equation (9), 1978, page 93.

${ }^{3}$ In addition, the labor market for $\mathrm{T}$ would have to be sufficiently competitive to remove constraints to wage level determination or available hours of employment.

${ }^{4} \mathrm{Also}$, as a result of confining our illustration to a one-period model, there is no investment. 


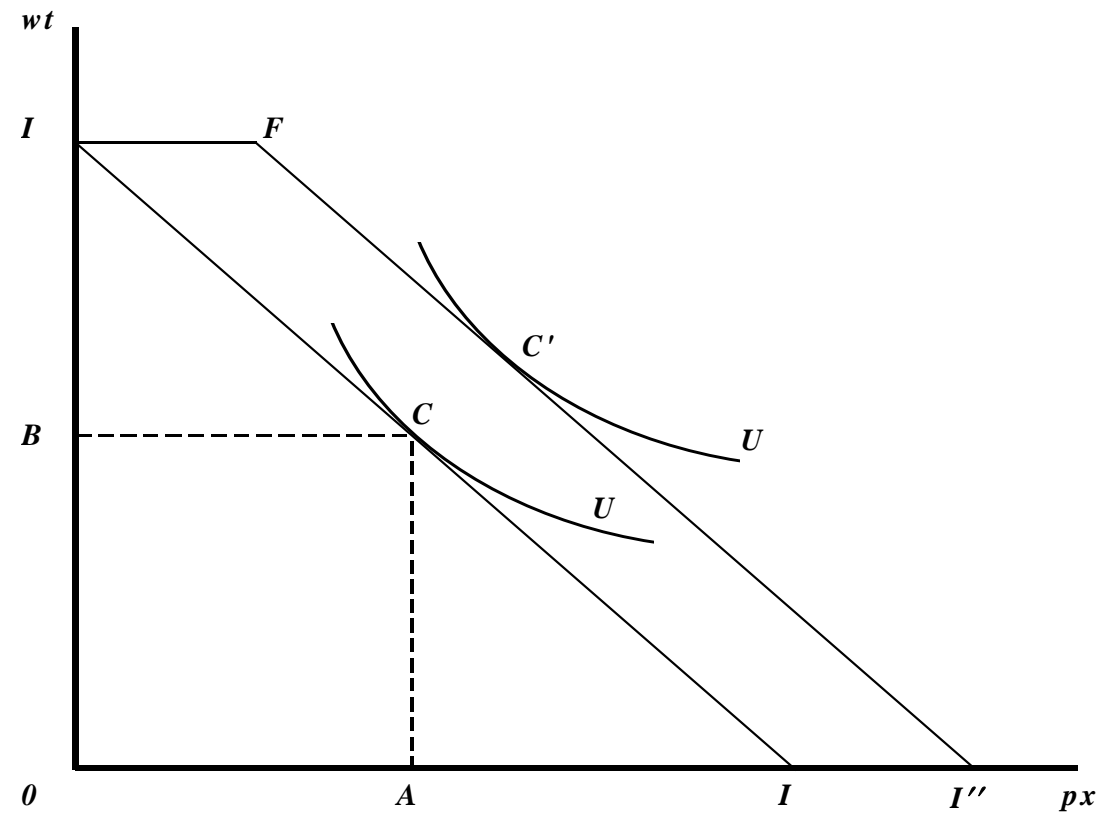

Figure 1. The Full-income Model with a Gift

Assume that the individual depicted in Figure 1 receives a monetary gift amount with value J. The full-income constraint now becomes I" F I where I" is I plus J. The new constraint's vertical axis intercept will not change due to the gift because the individual's production function for $\mathrm{Z}_{\mathrm{i}}$ is unchanged-the individual is not more or less productive as result of the gift. However, the monetary gift allows for increased utility to $\mathrm{C}^{\prime}$.

Now consider a different individual (with $\mathrm{V}=0$ ), depicted in Figure 2, who is in equilibrium at point C. Assume a reduction in this individual's productivity (which may be the result of an injury). As a result, w becomes aw where $0<\mathrm{a}<1$. In the case of injury, the estimation of a may be made by a medical, vocational, or other related expert. (Often aw would be less than the minimum wage.) A typical practice for economists is to estimate damages ${ }^{5}$ (pre-injury earnings minus post-injury earnings) by estimating the amount A-aA. Under the wholetime concept, this amount is inadequate to compensate the injured person.

Due to the diminished productivity of time, the full-income constraint in Figure 2 shifts from II to aIaI. (This shift from II to aIaI is in contrast to the change in the full-income constraint when hours of non-work time are on one axis and consumption of commodities is on the other axis; in which case the slope of the constraint changes.) An award of A-aA would result in the con-

${ }^{5}$ We omit discussion of the value of household services. Household services can be added to the model by the addition of a third axis or by considering the services to be a market good, $x$, with a price per unit (say per hour of service) of $p$, where $p=w$. 
straint aI D aI' where aI' is equal to aI plus the amount A-aA. An award of AaA does not allow the injured person to attain his or her pre-injury level of utility. The minimum amount of money which may provide the person his or her pre-injury level of utility is I-aI. This amount will provide the individual with the constraint aI E I which may enable the individual to attain his or her pre-injury level of utility.

Estimating the dollar amount that is required to place the individual back to $\mathrm{A}$ on the horizontal axis is a common and accepted damage calculation approach used by forensic economists. Estimating the dollar amount required to place the individual back to B on the vertical axis, however, has not been a common practice of forensic economists. The remainder of this paper and other papers in this symposium will address how to estimate such economic restoration.

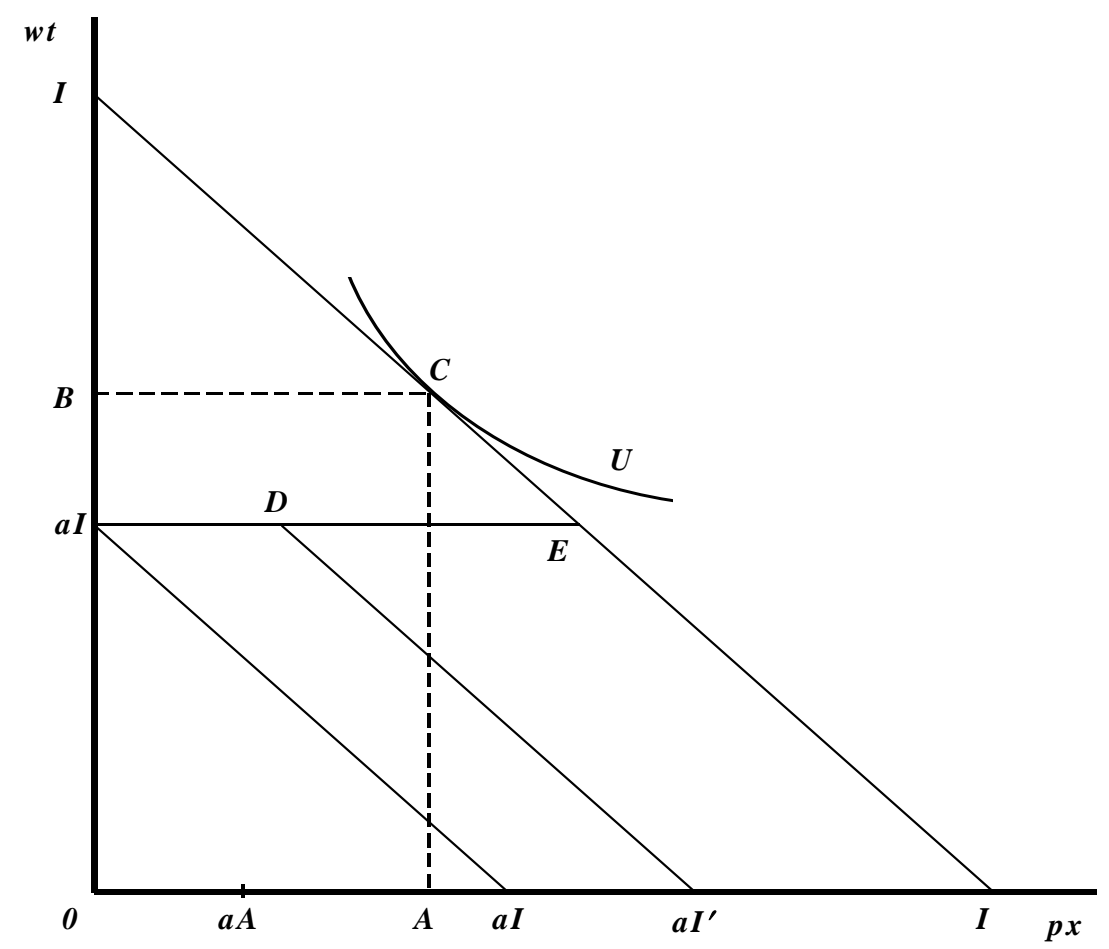

Figure 2. The Full-Income Model with an Injury 


\section{The Whole-time Calculation}

As an example of a whole-time calculation of economic losses due to personal injury, ${ }^{6}$ assume that a plaintiff, Mary Smith, has sufficient human capital to be an $\$ 18.00$ per hour wage earner. Mary becomes injured as result of a tort. A vocational expert determines that due to the physical limitations associated with the tort, Mary will only be able to secure employment at the wage level of $\$ 6.00$ per hour. One economist estimates Mary's economic loss of money income based on $\$ 12.00$ per hour in wage loss for 40 hours per week, $\$ 480$ per week.

Associated with the loss of money income, the value of the hours used in consumption must decline as these hours have the same economic value as the working hours. Using the whole-time concept, another economist opines that compensation of $\$ 480$ per week, the amount of the wage loss, would leave unaccounted economic losses to Mary Smith. This economist estimates Mary's weekly pre-injury full income to have been $\$ 1,764$. This amount is the product of 98 (the number of hours per week, 168, less 70 hours used for maintenance) and $\$ 18$. The economist computes whole-time damages as the minimum amount required to give Mary a portion of her pre-injury full-income constraint as $\$ 1,176$ per week $(\$ 1,764-(1 / 3) \times \$ 1,764$ where $1 / 3=\$ 6 / \$ 18)$.

\section{Conclusion}

Although the above example is simplistic, it illustrates the structure of the whole-time concept economic problem: an injury affecting the value of work time affects the value of time used for consumption by the same amount. Common forensic economic testimony focused on valuing working time alone cannot restore the pre-injury economic position of the plaintiff. In the balance of papers in this symposium, authors extend this introduction to the wholetime concept and outline the methods by which forensic economists can define and measure economic damages including the diminished economic value of non-work time.

\section{References}

Becker, Gary S., The Economic Approach to Human Behavior, Chicago: The University of Chicago Press, 1978.

Treatise on the Family Cambridge: Harvard University Press, 1991.

Ireland, Thomas R. and John O. Ward (editors), The New Hedonics Primer for Economists and Attorneys, Second Edition. Tucson: Lawyers and Judges Publishing, 1996.

${ }^{6}$ We do not imply that this very simple example encompasses all of the issues regarding measuring whole-time concept economic damages in the event of personal injury. 